\title{
COVID-19: O ISOLAMENTO SOCIAL E A GERAÇÃO DE RESÍDUOS SÓLIDOS NA CIDADE DE SÃO LUÍS-MA
}

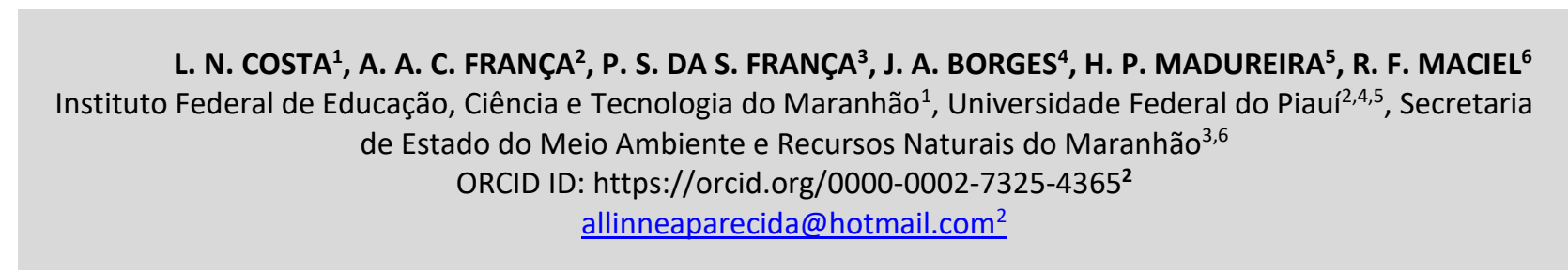

Submetido 21/07/2020 - Aceito 16/10/2020

DOI: $10.15628 /$ holos.2020.10786

\section{RESUMO}

Diante da pandemia de Covid-19, que se espalhou pelo mundo contaminando e matando milhares de pessoas, o isolamento social tem sido a principal medida adotada para reduzir o contágio pelo vírus, resultando em diferentes impactos sociais, econômicos e ambientais ao planeta. $\mathrm{O}$ trabalho em questão visa fazer um levantamento específico do impacto causado pelo isolamento social na geração de resíduos sólidos no município de São Luís durante o período de quarentena. Tendo em vista a existência de poucos estudos na área, o trabalho foi escrito baseando-se em artigos científicos, relatórios de órgãos responsáveis e informações oficiais do governo. Verificou-se que, contrariando as estatísticas, São Luís teve uma redução na geração de resíduos sólidos urbanos e a capital vem se destacando entre as principais cidades do Norte e Nordeste do Brasil que cumprem as determinações da PNRS. Apesar disso, o número de pessoas infectadas continua crescendo e é necessário estabelecer medidas de prevenção, assim como alternativas para a gestão adequada dos resíduos gerados, visto que a manutenção inapropriada dos mesmos pode aumentar o risco de transmissão do vírus.

PALAVRAS-CHAVE: pandemia, Sars-CoV-2, meio ambiente, resíduos sólidos urbanos, maranhão

\section{COVID-19: SOCIAL ISOLATION AND THE GENERATION OF SOLID WASTE IN THE CITY OF SÃO LUÍS-MA}

\begin{abstract}
In the face of the Covid-19 pandemic, which spread across the world, contaminating and killing thousands of people, social isolation has been the main measure adopted to reduce contagion by the virus, resulting in different social, economic and environmental impacts to the planet. The work in question aims to make a specific survey of the impact caused by social isolation in the generation of solid waste in the municipality of São Luís during the quarantine period. In view of the existence of few studies in the area, the work was written based on scientific articles, reports from responsible
\end{abstract}

agencies and official government information. It was found that, contrary to statistics, São Luís had a reduction in the generation of solid urban waste and the capital and has been standing out among the main cities in the North and Northeast of Brazil that comply with the PNRS. Despite this, the number of infected people continues to grow and preventive measures need to be established, as well as alternatives for the proper management of waste generated, since improper maintenance can increase the risk of transmitting the virus.

KEYWORDS: pandemic, Sars-CoV-2, environment, solid urban waste, maranhão 


\section{INTRODUÇÃO}

A COVID-19 é uma doença infecciosa causada pelo novo coronavírus, SARS-CoV2, geneticamente semelhante ao vírus responsável pela epidemia global da Síndrome Respiratória Aguda Grave (SARS) ocorrida entre 2002 e 2003 (Nghiem, Morgan, Donner e Short 2020).

A doença possui características semelhantes ao de uma gripe comum, age principalmente no trato respiratório causando quadros severos de pneumonia e, em todo o mundo, já são mais de onze milhões de casos confirmados e aproximadamente 550 mil mortes até a data de 09 de julho de 2020 (World Health Organization, 1948).

Até o presente momento, julho de 2020, ainda não existe uma vacina ou tratamento específico eficaz. Diante disso, a maioria dos países tenta combater a propagação do vírus com o estabelecimento de políticas públicas de distanciamento social, além do uso obrigatório de máscaras e álcool em gel (Zambrano-Monserrate, Ruano \& Sanchez-Alcalde 2020).

No Brasil, a pandemia de COVID-19 teve início em 26 de fevereiro de 2020 e em março, gradativamente, todos os governos estaduais determinaram medidas de isolamento social, mantendo em funcionamento apenas serviços considerados essenciais (MS-BR, 2020). O Maranhão, estado com aproximadamente sete milhões de habitantes, conforme última divulgação feita pelo Instituto Brasileiro de Geografia e Estatística (IBGE), iniciou o protocolo de quarentena na terceira semana de março. O Estado publicou decretos com suspensão das aulas da rede pública estadual e privada (Decreto no 18.884 do dia 16 de março de 2020); suspensão das atividades comerciais e de prestação de serviços (Decreto no 18.902, de 23 de março de 2020) e suspensão dos serviços de transporte intermunicipal de passageiros, na modalidade rodoviário (Decreto no 18.924 do dia 03 de abril de 2020) (Agência Brasil, 2020).

Em $1^{\circ}$ de maio de 2020, o governador do Maranhão decretou estado de lockdown em quatro municípios do estado (a capital São Luís, São José de Ribamar, Raposa e Paço do Lumiar) por pelo menos 10 dias, a iniciar no dia 5 de maio, respeitando uma ordem judicial imposta pelo Ministério Público protocolada no dia 30 de abril. Essa é a primeira situação de quarentena total no Brasil (Estadão, 2020).

Todas as medidas adotadas até o momento geraram de alguma forma, diferentes impactos ambientais, incluindo a gestão de resíduos sólidos urbanos (RSU) e resíduos biomédicos perigosos. Os estudos nessa área ainda são escassos, entretanto Kulkarni e Anantharama (2020) citam algumas investigações feitas até o momento em diferentes países e avaliam os diferentes aspectos da gestão de RSU durante as pandemias, analisando os vários tipos de resíduos gerados durante o surto de COVID-19 e os riscos potenciais de transmissão SARS-CoV-2 em países desenvolvidos e em desenvolvimento. De acordo com os autores, práticas de coleta inadequadas dos resíduos sólidos podem levar à contaminação com o vírus e aumentar o nível de transmissão.

Alguns estudos mostram também que na maioria dos países durante o período de emergência sanitária decorrente da Pandemia do COVID-19, o isolamento social e a prática do home office levaram a um aumento intenso na geração de resíduos domiciliares, orgânicos e inorgânicos (Zambrano-Monserrate, Ruano \& Sanchez-Alcalde 2020). No tocante à gestão dos 
Resíduos Sólidos, a cidade de São Luís segue se destacando no gerenciamento ambientalmente adequado dos resíduos sólidos urbanos, integrando o grupo de apenas $12 \%$ das cidades do Norte e Nordeste do Brasil que cumprem as determinações da Política Nacional de Resíduos Sólidos (PNRS). Freire et al. (2015) relatam que a quantidade de resíduos destinados a aterros e os resíduos dispostos a céu aberto diminuíram na cidade, após a implantação da PNRS na capital maranhense.

Diante disso e tendo em vista a necessidade de levantamentos de dados que possam auxiliar em estudos futuros na área, o trabalho em questão tem o objetivo de apresentar informações referentes a geração de resíduos sólidos na cidade de São Luís durante o período de isolamento social e propor medidas que auxiliem na gestão adequada, evitando maior propagação da doença.

\section{METODOLOGIA}

O presente trabalho se constitui pela abordagem qualitativa e quantitativa, de caráter exploratório e descritivo, embasado no levantamento bibliográfico e investigação de dados relacionados a geração de resíduos sólidos urbanos, assim como na análise crítica dos mesmos.

As informações sobre a quantidade de resíduos coletados no município de São Luís/MA foram fornecidas pelo Comitê Gestor de Limpeza Urbana do Município e compreendem o período de janeiro a maio de 2020. Os dados referentes aos resíduos hospitalares foram fornecidos pela MAXTEC, uma das empresas terceirizadas responsável pelo gerenciamento dos resíduos infectantes em São Luís.

Os dados foram organizados em tabela e gráficos para melhor exposição dos dados, e para isso foram utilizadas planilhas do Microsoft Word e Excel.

\section{RESULTADOS E DISCUSSÃO}

Fazendo um apanhado sobre a geração de resíduos sólidos urbanos em anos anteriores, viu-se que no ano de 2010 houve uma geração estimada em torno de 5.733 toneladas por dia de Resíduos Sólidos Urbanos (RSU), o que corresponde a uma geração de 2.092 .545 toneladas de RSU por ano no estado. Documentos da ABRELPE (2020) e do IBGE (2020) revelam que o aumento da população urbana na capital maranhense influenciou diretamente nas taxas de aumento da produção dos resíduos sólidos. De 2011 para 2012, a população chegou a 4.238 .099 habitantes, (aumento de $1,07 \%$ ) o que refletiu em um aumento de $1,69 \%$ da geração de RSU no mesmo período, chegando a gerar 6.754 t/dia em 2012. Houve um aumento de $3,84 \%$, na taxa de resíduos sólidos coletados chegando a ser coletado $4.061 \mathrm{t} /$ dia no ano de 2012 , o que corresponde a $60 \%$ do total de resíduos gerados no Estado. A taxa de resíduos sólidos coletados per capita teve aumento de 2,68\%, chegando a 0,958 kg/hab./dia em 2012.

No ano de 2015 a população total do Estado contava com 6.904.241 habitantes e 7.296 t/dia de RSU gerados e 4.340 t/dia de RSU coletados; em 2016 por sua vez, houve um discreto 
aumento no número populacional, com 6.954.036 de habitantes e 7.173 t/dia de RSU gerados e 4.271 de RSU coletados (ABRELPE, 2020).

A Tabela 1 apresenta os dados de resíduos coletados no município de São Luís/MA fornecidos pelo Comitê Gestor de Limpeza Urbana do Município no período de janeiro de 2020 a maio de 2020.

Tabela 1- Resíduos coletados nas praias e no município de São Luís/M/A

\begin{tabular}{l|c|c|c|c|c}
\hline & Janeiro/2020 & Fevereiro/2020 & Março/2020 & Abril/2020 & Maio/2020 \\
\hline & & & & & \\
Coleta Domiciliar & $26.200,86$ & $22.970,54$ & $24.810,42$ & $22.823,40$ & $23.312,03$ \\
Demais serviços* & $14.556,92$ & $13.829,80$ & $13.203,66$ & $11.955,52$ & $12.299,12$ \\
& & & & & \\
\hline
\end{tabular}

*os dados referentes ao item Demais serviços inclui o quantitativo de resíduos coletados nos terminais rodoviários, comércios, ruas e parques, excluindo o quantitativo de materiais recicláveis dos Ecopontos e da coleta seletiva.

Os dados apresentados corroboram com o balanço realizado pela Associação Brasileira de Empresas de Limpeza Pública e Resíduos Especiais (Abrelpe) e pela Associação Internacional de Resíduos Sólidos no Brasil (ISWA, 2020) que mostrou que a geração de resíduos domiciliares (RD) no país caiu 7,25\%, em abril, comparando com o mesmo período do ano passado. A pesquisa foi realizada junto a empresas que representam $60 \%$ do mercado privado de limpeza urbana atuantes em todas as regiões do Brasil. Essa redução da geração de RD caminha na direção oposta ao projetado pela Abrelpe, que estimou um aumento de 15 a 20\% dos resíduos domiciliares como efeito da quarentena, isolamento e distanciamento social.

Uma possível explicação para essa diminuição seria o atual cenário do Brasil que é de instabilidade e retração econômica, gerando incertezas e contenção por parte dos consumidores. Uma vez que a geração de resíduos tem relação direta com o poder aquisitivo e hábitos de consumo de cada sociedade, esta é induzida pela situação econômica de um país. Outro fator relevante foi a redução das atividades econômicas. Com as medidas de restrições, como por exemplo, o lockdown, que tinha como objetivo impedir o fluxo de pessoas e conter o vírus, muitas atividades e trabalhadores se impossibilitaram de produzirem, com isso houve queda da procura de produtos e serviços, assim como redução do consumo e consequente geração de resíduos.

É possível observar através dos Gráficos 1 e 2 que a taxa de isolamento social influenciou na quantidade de resíduos gerados. Pode-se notar que no mês de março, início do período pandêmico, houve a maior taxa de produção de resíduos sólidos e a taxa de isolamento foi a menor dentre os meses apresentados $(40,2 \%)$, visto que as medidas de restrição só tiveram início a partir da terceira semana do mês citado. Vale ressaltar que a taxa apresentada se trata de uma média aritmética e inclui a quantidade de resíduos gerados durante todo o mês. 


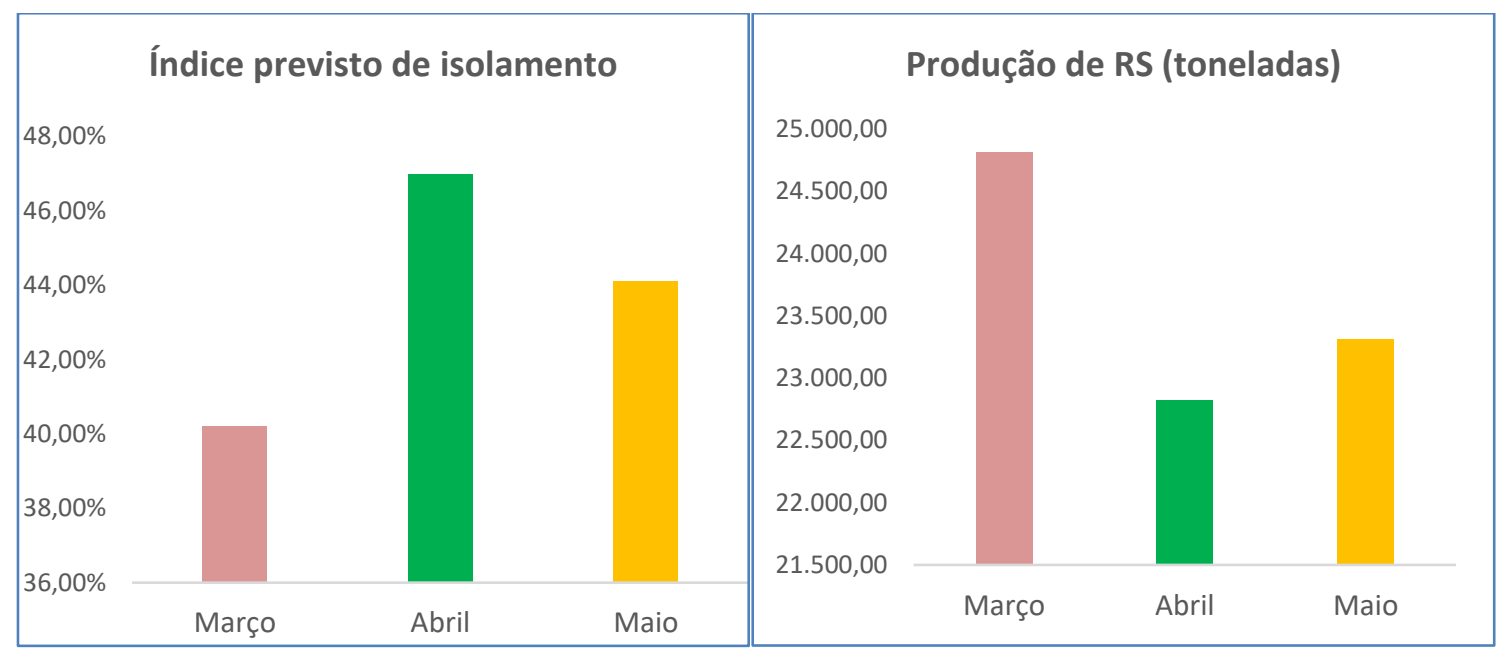

Gráfico 1: Taxas de isolamento

Gráfico 2: Produção de resíduos sólidos

No mês de abril, com o aumento do número de casos de Covid-19 e a adoção de medidas mais rigorosas para conter a evolução da pandemia, observa-se uma diminuição no quantitativo de resíduos domiciliares gerados. Essa redução reforça a ideia de relação com as medidas mais restritivas de isolamento social. Observa-se que durante o mês de maio a geração de resíduos sólidos sofreu novamente um aumento visto que houve um afrouxamento nas medidas de isolamento e a divulgação da reabertura gradual das atividades econômicas feita em pronunciamento público pelo governador do Estado no dia 20 de maio .

Deve-se levar em conta que as intensas atividades comerciais ocorrem na área central de São Luís, onde há uma concentração maior de lojas de diversos segmentos, restaurantes e bares, e como esses estabelecimentos não são considerados essenciais, o funcionamento foi suspenso, o que interfere diretamente no número de materiais descartados. Assim, pode-se associar a diminuição da produção de resíduos na capital maranhense, com o equilíbrio que ocorreu entre a paralisação das atividades de bares, restaurantes, empresas e a presença menor de moradores da Região Metropolitana circulando na cidade, influenciando no quantitativo de resíduos gerados pelos Demais serviços.

O termo Demais Serviços (Tabela 1) refere-se ao lixo comercial e resíduos gerados na limpeza de ruas, manutenção de parques e serviços de varrição em geral, não incluindo resíduos coletados nos Ecopontos, equipamentos que tem como objetivo permitir um local para a destinação ambientalmente adequada dos resíduos recicláveis e volumosos para a população da cidade. Atualmente, São Luís tem 18 Ecopontos em pleno funcionamento, e estes foram o primeiro programa de coleta seletiva implantada na cidade. Antes da implantação, parte significativa dos resíduos recicláveis eram descartados irregularmente nas vias públicas, formando pontos de acúmulo conhecidos como lixeiras viciadas. Estes equipamentos permitem à população a correta separação e o descarte ambientalmente adequado dos resíduos sólidos, evitando que sejam descartados incorretamente nas vias públicas (Agência de Notícias, 2020).

Quanto ao lixo hospitalar, a Associação Brasileira de Recuperação de Energia e Resíduos aponta que o Brasil tem a capacidade de produzir anualmente cerca de 480 mil toneladas de resíduos de serviços de saúde. Até o momento foram produzidas 253 mil toneladas. Estima-se que 
esse número quadriplique diante do uso obrigatório de EPIS, como máscaras faciais e luvas em unidades de saúde, além dos materiais de uso pessoal de cada paciente. Todos esses resíduos se gerenciados incorretamente, podem representar ameaças ambientais e à saúde, especialmente quando se considera que o coronavírus pode sobreviver em superfícies materiais (por exemplo, metais, vidro e plásticos) por até 9 dias (Kampf, Todt, Pfaender, Steinmann 2020).

De acordo com os dados fornecidos pela MAXTEC, uma das empresas terceirizadas responsável pelo gerenciamento dos resíduos infectantes em São Luís, houve um aumento considerável na quantidade de resíduos hospitalares gerados no mês de maio (Ver Gráfico 2). São Luís é considerada um dos epicentros da doença no País e atingiu a marca de 9255 contaminados e 526 mortes nesse período.

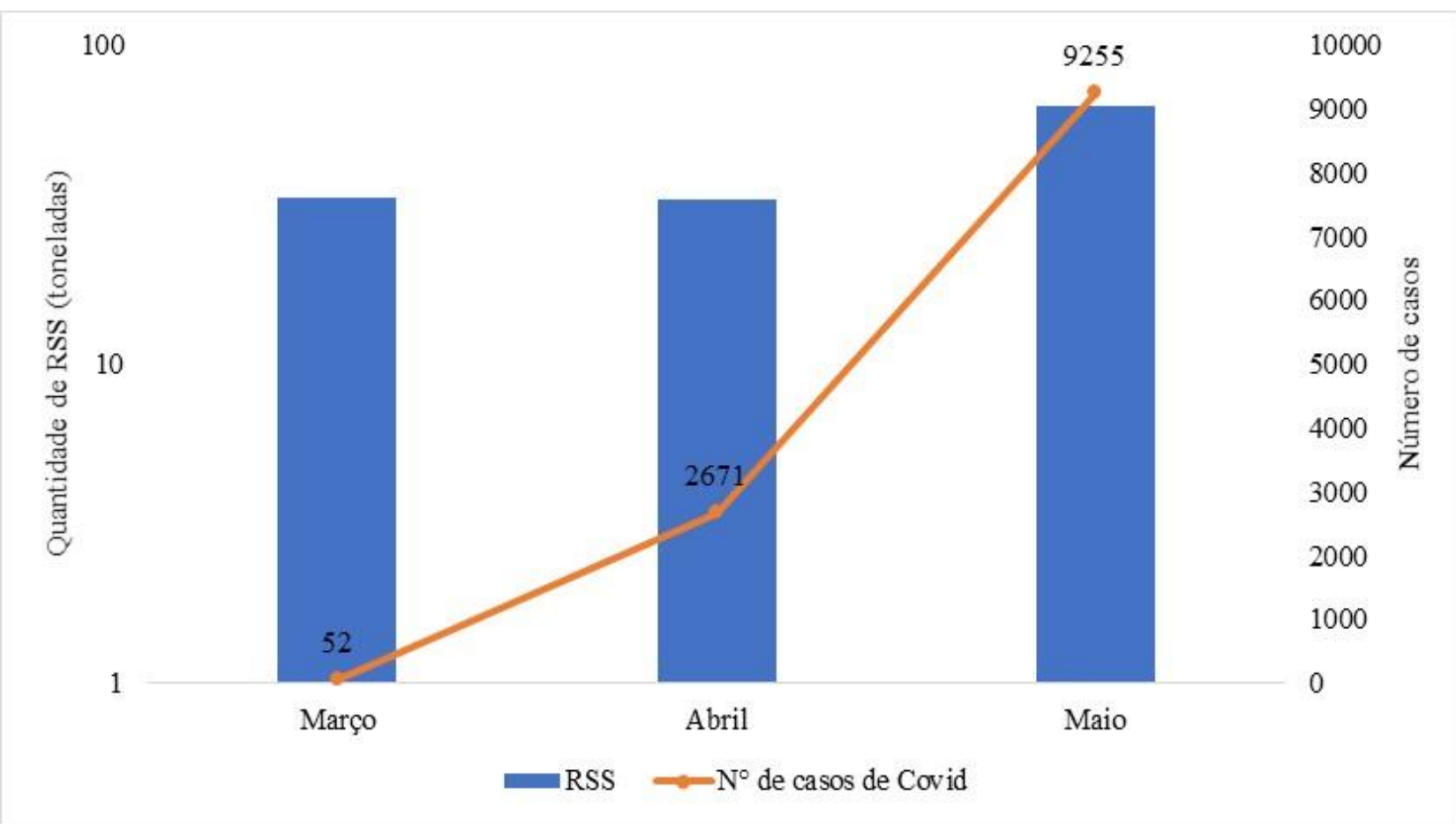

Gráfico 2: Geração de Resíduos de Serviços de Saúde x número de casos de Covid-19 na cidade de São Luís

O aumento no volume de resíduos hospitalares é proporcional ao índice de contaminação por Covid-19, representando uma das principais problemáticas à saúde e meio ambiente quando não se tem a destinação adequada. De acordo com a ABREN (2020), 36,2\% dos resíduos hospitalares do país são destinados a aterros ou lixões sem nenhum tratamento, colocando em risco a saúde pública e agravando a disseminação de doenças.

Diante disso, o alto risco de contágio pelo novo coronavírus tem reforçado a necessidade de cuidar ainda mais dos procedimentos de coleta e descarte adequado de resíduos sólidos urbanos (RSU) e Resíduos dos Serviços de Saúde (RSS) (Araújo e Silva, 2020). Entre as alternativas viáveis para o tratamento de resíduos contaminantes está o tratamento térmico, recomendado pela Organização Mundial da Saúde (OMS). 
Em carta enviada ao Ministério da saúde, Yuri Schmitke, presidente da ABREN, cita que que a China recicla 35\% e incinera (tratamento térmico) 40\% do lixo urbano, gerando energia limpa e eliminando o risco de contaminação causado pelo lixo. A Europa recicla $47 \%$ e incinera $28 \%$ dos seus resíduos sólidos urbanos, sendo que países como o Japão, a incineração chega a 70\%. Tais países possuem elevados índices de tratamento de resíduos e baixo gasto com a saúde pública decorrente do manejo do lixo urbano (ABREN 2020).

Outra possibilidade de redução dos impactos gerados com a destinação inadequada dos resíduos sólidos é a recuperação utilizando o potencial social, econômico e ambiental, adotando uma ordem de prioridade com preconiza a PNRS, a saber: não geração, redução, reutilização, reciclagem, tratamento e disposição apenas dos rejeitos. Os resíduos domiciliares orgânicos, por sua vez, podem ser reaproveitados através da compostagem (Zago e Barros, 2019).

Para Monteiro (2001) a compostagem caracteriza-se por um processo natural, de ação de microrganismos que decompõem biologicamente os materiais orgânicos de origem animal e vegetal. Independente da tecnologia adotada é importante enfatizar que os resíduos precisam estar disponíveis. Para isso, a implementação da coleta seletiva busca auxiliar para que haja uma redução de resíduos destinados aos aterros. A coleta seletiva é um sistema diferenciado de coleta dos materiais recicláveis, segregado na fonte: plástico, vidro, metais, papel e orgânicos (PintoCoelho, 2009).

Durante a pandemia a prestação dos serviços públicos de coleta, transporte e destinação dos resíduos em São Luís foram mantidos, sendo essenciais para conservar o ambiente limpo e auxiliar na redução da disseminação do vírus (DECRETO № 35.677, DE 21 DE MARÇO DE 2020). É importante que haja cuidado por parte da população acerca do manejo dos resíduos nos domicílios antes de serem recolhidos para que não afetem a saúde dos profissionais que desenvolvem o trabalho de coleta. Os coletores, embora utilizem equipamentos de proteção e em condições anteriores a pandemia já atuavam em cenário de vulnerabilidade, no contexto do COVID-19, estão ainda mais expostos.

Os resíduos gerados no ambiente domiciliar que não possuem suspeita e nem confirmação de indivíduo com COVID-19, devem ser gerenciados conforme procedimentos comumente executados. Não há necessidade de medidas drásticas, mas são necessários alguns cuidados adicionais para que garanta a saúde da população e dos trabalhadores, como: ensacar os resíduos com sacos resistentes, descartáveis e preenchidos com até dois terços da capacidade e serem destinado conforme calendário de coleta. Já as residências domiciliares que existem confirmação ou suspeita de morador, que executam o isolamento domiciliar, devem seguir procedimentos específicos, uma vez que os resíduos produzidos por estes indivíduos e por quem presta assistência, possuem risco de contaminação para os demais moradores, assim, como para os coletores (SEMA, 2020).

No cômodo da residência em que o paciente se encontra isolado, recomenda-se disponibilizar uma lixeira de uso particular, que seja coberta com saco resistente, onde todos os resíduos gerados, com potencial risco de contaminação, serão armazenados. Estes resíduos não devem ser acumulados por muitos dias. Os materiais como máscaras, luvas, entre outros, devem 
ser colocados em sacos plásticos duplos e devidamente fechados para em seguida direcioná-los a coleta (SEMA, 2020).

Os resíduos provenientes das unidades de atendimento à saúde devem seguir regulamentação inerente aos resíduos infectantes Grupo A (sub grupo A1), de acordo com Resolução ANVISA RDC n²22, de 28 março de 2018 e a Resolução do Conselho Nacional de Meio Ambiente (CONAMA) 358/2005. Estes resíduos necessitam de um manejo diferenciado, ou seja, um tratamento inicial antes da sua disposição final, pois possuem agentes biológicos, conforme Classificação de Risco do Ministério da Saúde, e por essas características, apresentam risco de infecção. De acordo com as Resoluções citadas, devem ser acondicionados em saco vermelho, caso haja condições que seja duplo, e substituídos quando atingirem $2 / 3$ da capacidade, ou então a cada 48 horas. Os sacos devem possuir simbologia de substância infectante e precisam estar contidos em recipientes que facilitem a lavagem, resistentes à punctura, ruptura, vazamento e tombamento, que possuam tampas providas de sistema de abertura sem contato manual. Por ser característico dos Resíduos de Serviço de Saúde, esse material gerado deve sofrer coleta e transporte especializado e destinados a procedimentos de tratamento e disposição final licenciado pelo Órgão Ambiental Competente.

\section{CONCLUSÃO}

A partir do levantamento de dados realizado e das informações coletadas verificou-se que o isolamento social provocado pela pandemia de Covid-19 na cidade de São Luís influenciou diretamente na taxa de resíduos sólidos gerados no período entre março e maio de 2020 . Contrariando a média mundial de crescimento de resíduos domiciliares durante a pandemia, São Luís mostrou uma redução na quantidade de resíduos gerados no mês de abril, período em que a cidade atingiu as maiores taxas de isolamento social. Quanto ao lixo hospitalar, como já era esperado, o aumento de casos de pessoas contaminadas elevou o número de resíduos infectantes. Diante disso, torna-se essencial a conscientização da população no manuseio adequado desses materiais, de forma a evitar a propagação da doença.

\section{REFERÊNCIAS}

Abrelpe - Associação Brasileira de Empresas de Limpeza Pública e Resíduos Especiais. (1976). ABRELPE NO COMBATE A COVID -19. Recuperado em 10 de abril de 2020 de http://abrelpe.org.br/.

Araújo, E. C. S.; Silva, V. F. (2020). A gestão de resíduos sólidos em época de pandemia do Covid19. GeoGraphos; 129(11), 215.

Associação Brasileira de Engenharia Sanitária e Ambiental (ABES). (1966). Recomendações para a Gestão de Resíduos em Situação de Pandemia por Coronavírus (COVID-19). Recuperado em 26 de junho de 2020, de http://www2.mma.gov.br/port/conama/legiabre.cfm?codlegi=462. 
Agência Brasil, 2020. Recuperado em 2 de abril de 2020 de https://agenciabrasil.ebc.com.br/saude/noticia/2020-03/veja-medidas-que-cada estadoesta-adotando-para-combater-covid-19.

Associação Brasileira de Recuperação Energética de Resíduos (ABREN). Ministro da Saúde recebe recomendação da ABREN para incinerar lixo contaminado. Recuperado em 24 de junho de 2020 de https://abren.org.br/2020/03/01/ministro-da-saude-recebe-recomendacao-daabren-para-incinerar-lixo-contaminado/.

Boletins Covid-19. Recuperado em 07 de julho de 2020 de http://www.saude.ma.gov.br/boletinscovid-19/.

ESTADÃO: JORNAL DIGITAL. Recuperado em 15 de junho de 2020 de https://saude.estadao.com.br/noticias/geral,maranhao-vai-aplicar-lockdown-em-quatromunicipios-da-regiao-metropolitana-de-sao-luis,70003289853.

IBGE - Instituto Brasileiro de Geografia e Estatística. (1934). Estimativas da população residente para os municípios e para as unidades da federação. Recuperado em 10 de abril de 2020, de https://www.ibge.gov.br/pt/inicio.html.

ISWA - A International Solid Waste Association. (2020). COVID-19 News. Recuperado em 10 de abril de 2020 de https://www.iswa.org/.

Kampf, G., Todt, D., Pfaender, S., Steinmann, E. (2020). Persistence of coronaviruses on inanimate surfaces and their inactivation with biocidal agents. J. Hospital Infect, 104(3), 246-251.

Kulkarni, B. N., Anantharama, V. (2020) Repercussions of COVID-19 pandemic on municipal solid waste management: Challenges and opportunities. Science of the Total Environment, 743, 140693.

MINISTÉRIO DA SAÚDE (BR). (1953). Recuperado em 15 de junho de 2020, de http://www2.mma.gov.br/port/conama/legiabre.cfm?codlegi=462

Monteiro. J. H. P. (2001). Manual de Gerenciamento Integrado de resíduos sólidos. Coordenação técnica Victor Zular Zveibil. Rio de Janeiro: IBAM.

Como o meio ambiente reage à redução da atividade econômica. NEXO, 2020. Recuperado em 16 de junho de 2020 de https://www.nexojornal.com.br/expresso/2020/05/04/Como-o-meioambiente-reage-\%C3\%A0-redu\%C3\%A7\%C3\%A3o-da-atividade-econ\%C3\%B4mica.

Nghiem, L. D., Morgan, B., Donner, E., Short, M. D. (2020). The COVID-19 pandemic: Considerations for the waste and wastewater services sector. Case Studies in Chemical and Environmental Engineering, 1: 100006.

Pinto-Coelho, R. M. (2009). Reciclagem e desenvolvimento sustentável no Brasil. Belo Horizonte: Recóleo.

Resolução Conama no 358, de 29 de abril de 2005. (2005). Brasília. Recuperado em 26 de junho de 2020, de http://www2.mma.gov.br/port/conama/legiabre.cfm?codlegi=462. 
SÃO LUÍS anuncia retorno da coleta seletiva e programa de desconto para incentivar descarte de recicláveis nos Ecopontos. São Luís - Agência de Notícias, 2020. Recuperado em 04 de junho de 2020 de https://www.agenciasaoluis.com.br/noticia/28589/.

Secretaria de Estado do Meio Ambiente e Recursos Naturais (SEMA). Orientações Sobre a Gestão das Máscaras no Contexto do COVID-19. Recuperado em 26 de junho de 2020, de http://www2.mma.gov.br/port/conama/legiabre.cfm?codlegi=462.

World Health Organization. (1948). Recuperado em 18 de junho de 2020, de https://www.who.int/emergencies/diseases/novel coronavirus-2019.

Zago, V. C. P., Barros., R. T. V. (2019). Gestão dos resíduos sólidos orgânicos urbanos no Brasil: do ordenamento jurídico à realidade. Engenharia Sanitária Ambiental; 24(2), 219.

Zambrano-Monserrate, M. A., Ruano, M. A., Sanchez-Alcalde, L. (2020). Indirect effects of COVID19 on the environment. Science of the Total Environment; 728(1), 138813.

\section{COMO CITAR ESTE ARTIGO:}

Costa, L. N., França, A. A., França, P. S. da S., Borges, J. A., Madureira, H. P., Maciel, R. F. (2020). Holos. 36 (5), 1-11.

\section{SOBRE OS AUTORES}

\section{N. COSTA}

Professora de Química do ensino básico, técnico e tecnológico do Instituto federal do Maranhão - IFMA e doutoranda em Química pela Universidade Federal do Piauí com ênfase na área de físico-química. E-mail: ludyane.costa@ifma.edu.br ORCID ID: https://orcid.org/0000-0002-7325-4365

\section{A. A. C. FRANÇA}

Doutoranda em Química / UFPI. E-mail: allinneaparecida@ hotmail.com

ORCID ID: https://orcid.org/0000-0003-1456-298X

\section{P.S. DA S. FRANÇA}

Engenheiro Ambiental. Supervisor de Resíduos Sólidos da secretaria de estado do meio ambiente e recursos naturais (SEMA). E-mail: pablo.seixas@ sema.ma.gov.br

ORCID ID: https://orcid.org/0000-0003-1724-7950

\section{J. A. BORGES}

Doutoranda em Química / UFPI. E-mail: joyceab.88@gmail.com

ORCID ID: https://orcid.org/0000-0003-1724-7950

\section{H. P. MADUREIRA}

Mestrando em Ciências dos Materiais / UFPI. E-mail: hunos.paixao@gmail.com

ORCID ID: https://orcid.org/0000-0001-8786-2444

\section{R. F. MACIEL}

Secretário adjunto de licenciamento ambiental da secretaria de estado do meio ambiente e recursos naturais (SEMA). E-mail: rafael.maciel@sema.ma.gov.br

ORCID ID: https://orcid.org/0000-0001-5627-4578 
Editor(a) Responsável: Francinaide de Lima Silva Nascimento Pareceristas Ad Hoc: JOSÉ BELDSON RAMOS e ÁLEFE VIANA

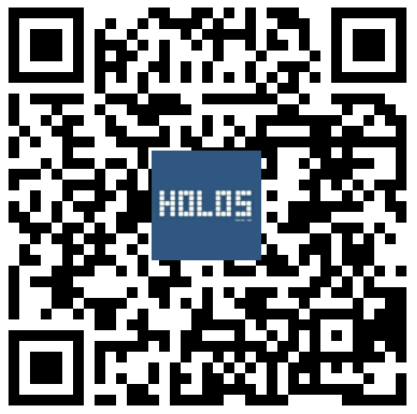

